\title{
Stability of neomycin resistance in Staphylococcus aureus
}

\author{
G. A. J. AYLIFFE \\ From the Hospital Infection Research Laboratory, Summerfield Hospital, Birmingham
}

SYNOPSIS A strain of Staphylococcus aureus isolated from the skin of a subject with eczema showed a loss in resistance to neomycin and tetracycline after treatment with neomycin was stopped. Seven out of 22 strains of neomycin-resistant Staph. aureus showed a loss in resistance to neomycin and streptomycin after storage in nutrient broth for 14 days at room temperature, and it seems probable that resistance in these unstable strains was controlled by extrachromosomal elements or plasmids. Strains of phage types 84/85 and 29/77 and related types were frequently isolated in general hospital wards and showed no loss in resistance on similar storage in nutrient broth. Five of the neomycin-unstable strains were isolated from patients with eczematous lesions. Multiple-resistant and antibiotic-sensitive strains of Staph.aureus of similar phage type were isolated from patients in a ward for patients with skin disease, and the possibility of transfer of resistance in vivo is discussed.

The selection of neomycin-resistant strains of Staph. aureus by neomycin or related compounds and the disappearance after discontinuing the use of these antibiotics has been shown in a burns unit (Lowbury, Babb, Brown, and Collins, 1964) and in a surgical ward (Alder and Gillespie, 1967). Neomycin resistance in the strains isolated from the burns unit appeared to be stable and the gradual disappearance of resistant strains over a period of six months was due to a reduction in the numbers of resistant organisms rather than to a specific loss of neomycin resistance in strains remaining in the unit. By contrast, a strain showing unstable resistance to neomycin was isolated from the skin of a profuse disperser with eczema who was being treated with a topical neomycin preparation (Ayliffe and Collins, 1967).

Received for publication 13 May 1969
In the present study, changes in resistance to antibiotics of Staph. aureus isolated from the eczematous subject after discontinuing treatment with neomycin were investigated. Studies were made on the loss of neomycin resistance on storage of neomycin-resistant strains isolated from a number of patients in different hospital environments. Variations in antibiotic sensitivity patterns of staphylococci of similar phage type isolated from patients in a skin hospital are also described.

\section{Methods}

SAMPLING OF PATIENTS

Nasal swabs and swabs from lesions were collected from patients in cross-sectional surveys of 14 hospitals in the Birmingham region. A 
number of skin sites of patients in a hospital for skin diseases were sampled with Alne disposable contact plates (a modification of the method described by Hall and Hartnett, 1964). Samples were taken by pressing the agar surface of the contact plate onto the skin. The skin of the staphylococcal disperser (S) was sampled while he was treated with a topical neomycin preparation and two months after discontinuing its use. A varicose ulcer on the leg of a patient in a surgical ward was also sampled before and after a period of two months without antibiotic treatment.

SAMPLING OF THE ENVIRONMENT In a cross-sectional survey of a hospital for diseases of the skin, floors were sampled with contact plates.

\section{BA CTERIOLOGY}

Nasal swabs were cultured on nutrient agar containing phenolphthalein diphosphate (Barber and Kuper, 1951). Swabs from lesions were cultured on blood agar and McConkey's medium. Alne contact plates were filled with nutrient agar containing phenolphthalein diphosphate to provide a surface raised slightly above the rim of the plate. All plates were incubated for 18 hours at $37^{\circ} \mathrm{C}$ and colonies of presumptive Staph. aureus were confirmed by slide or tube coagulase tests. Strains of Staph. aureus were tested for sensitivity to antibiotics by the ditchplate method. The ditches contained the following concentrations of antibiotics: benzylpenicillin, 10 units $/ \mathrm{ml}$; novobiocin, lincomycin, fusidic acid, erythromycin, and methicillin, $10 \mu \mathrm{g} / \mathrm{ml}$; streptomycin, tetracycline, chloramphenicol, and neomycin, $50 \mu \mathrm{g} / \mathrm{ml}$. Strains from the skin hospital were also tested for resistance to bacitracin $(50 \mu \mathrm{g} / \mathrm{ml}$ in the ditch). Staphylococci were phage typed with the routine set of phages kindly supplied by the Central Public Health Laboratory, Colindale. Organisms were stored on agar slopes in bijou bottles at room temperature.

TESTS FOR STABILITY OF ANTIBIOTIC RESISTANCE OF Staph. aureus ISOLATED FROM TWO PATIENTS

One hundred and twenty-seven colonies of Staph. aureus (phage type 80/81 at 1,000 $\times$ routine test dilution) isolated from the skin of the staphylococcal disperser (S) were tested for sensitivity to antibiotics. Two months after discontinuing topical treatment with neomycin, the skin of the disperser was again sampled and 100 colonies of Staph. aureus were tested for sensitivity to antibiotics. One hundred colonies of neomycin-resistant Staph. aureus (phage type 85) from the varicose ulcer of another patient were also tested for sensitivity to anIPbiotics before and after two months witho antibiotic treatment. A number of colonies from both patients before and after treatme were phage typed.

TESTS FOR STABILITY OF ANTIBIOTIC RESISTANCE OF Staph. aureus ON STORAGE Twenty-five neomycin-resistant strains were test $\bar{d}$ again for sensitivity to antibiotics after storage on agar slopes for periods varying from three months to two years. Resistance to neomycim was lost in three strains, resistance to streptomycin was also lost in one of these strais (phage type 52A), and resistance to fuside acid was also lost in another strain (phage type $29 / 52 / 52 \mathrm{~A}$ at $1,000 \times$ routine test dilution).

Single colonies from the other 22 neomycinresistant strains were inoculated into nutrient broth and incubated for 18 hours at $37^{\circ}$. Nutrient agar plates were inoculated with the broth cultures diluted to give approximately $2 \overline{80}$ colonies per plate. Replicates were made from these plates onto nutrient agar plates containimg $20 \mu \mathrm{g} / \mathrm{ml}$ neomycin sulphate. The broth cultures were then stored for 14 days at room temperatupe after which they were again inoculated on agar plates, from which replica plates were taken on medium containing neomycin. In strahs showing any neomycin-sensitive colonies, 1000 colonies were selected at random from subcultures on agar plates made after 18 hougs, incubation and after 14 days' storage. Thêse colonies were tested for sensitivity to the fQll range of antibiotics.

Minimum inhibitory concentrations (M安) of neomycin for resistant and sensitive varianits of three strains, two strains showing stable resistance, and the Oxford staphylococcus wegre determined by a broth dilution method.

Extrachromosomal elements or plasmids centrolling resistance to antibiotics may sometines be eliminated by growing the organism gin nutrient broth containing acriflavine (Mitsuhashi, Hashimoto, Kono, and Marimura, 1963) or 9 n nutrient broth at $44^{\circ} \mathrm{C}$ (Asheshov, 1966). Tests for loss of resistance to neomycin using these methods were made with the 22 strains.

\section{Results}

STABILITY OF ANTIBIOTIC RESISTANCE OF Staph. aureus ISOLATED FROM TWO PATIENTS

Loss of resistance to neomycin and tetracyci্⿳亠丷厂巾 of staphylococci isolated from the skin of the disperser (S) after discontinuing treatment for two months is shown in Table I. Resistanceôtto neomycin or tetracycline was sometimes Fost independently; resistance to novobiocin appea⿳亠丷厂犬. 
to be stable. No loss in resistance to any antibiotic occurred in staphylococci isolated from the varicose ulcer after two months without antibiotic treatment. Phage types of strains isolated from both patients remained unchanged during the two-month interval without treatment.

\begin{tabular}{lcccc}
\hline $\begin{array}{l}\text { Time of Isolation } \\
\text { of Staphylococci }\end{array}$ & $\begin{array}{l}\text { No. of } \\
\text { Colonies } \\
\text { Tested }\end{array}$ & \begin{tabular}{c} 
Percentage of Colonies Sensitive to \\
\cline { 3 - 5 }
\end{tabular} & $\begin{array}{l}\text { Tetra- } \\
\text { cycline }\end{array}$ & Novobiocin Neomycin \\
\hline $\begin{array}{l}\text { During treatment } \\
\text { Two months after } \\
\text { discontinuing } \\
\text { treatment }\end{array}$ & 127 & 0 & 0 & 2 \\
\hline
\end{tabular}

Table I Loss of antibiotic resistance in Staph. aureus on discontinuing treatment of disperser with neomycin cream

\section{STABILITY OF ANTIBIOTIC RESISTANCE} ON STORAGE

The stability of neomycin-resistance in 22 strains is shown in Table II. Strains of phage types $84 / 85,85$, and $29 / 77$ showed stable resistance in these tests, but most of the other strains showed varying degrees of reversion to sensitivity. The five strains isolated from the skin of eczematous patients were particularly unstable. However, three of these were of related phage patterns and isolated from patients in the skin hospital, although not all at the same time. One of the unstable strains (phage type $80 / 81$ at $1,000 \times$ routine test dilution) was isolated from the disperser (S). Five of the unstable strains were sensitive to penicillin, but were resistant to two or more other antibiotics.

Streptomycin resistance as well as neomycin resistance was lost in the unstable strains; not all neomycin-resistant strains, however, were initially resistant to streptomycin. No other loss in resistance to other antibiotics was found.

The MIC of neomycin for sensitive variants was $2-4 \mu \mathrm{g} / \mathrm{ml}$, which was slightly higher than that for the Oxford staphylococcus $(0.5 \mu \mathrm{g} / \mathrm{ml})$. The MIC for the resistant variants and for strains showing stable neomycin resistance was $>128 \mu \mathrm{g} / \mathrm{ml}$.

No increased loss in resistance to neomycin occurred on growing the stable or unstable strains in nutrient broth containing acriflavine or at $44^{\circ} \mathrm{C}$.

\section{STRAINS ISOLATED FROM PATIENTS WITH SKIN DISEASES}

Table III shows strains of similar phage pattern but different antibiotic sensitivity patterns isolated from patients in a hospital for diseases of the skin on one day. A strain resistant to five antibiotics and a strain sensitive to all the antibiotics tested was isolated from the skin of one patient. Resistance to neomycin and streptomycin, but not to other antibiotics, was lost on storing neomycin-resistant strains in broth for

\begin{tabular}{lll}
\hline $\begin{array}{l}\text { No. of } \\
\text { Isolates }\end{array}$ & $\begin{array}{l}\text { Antibiotic } \\
\text { Resistance } \\
\text { Pattern }\end{array}$ & $\begin{array}{l}\text { Phage Pattern } \\
\text { (RTD) }\end{array}$ \\
\hline 4 & P S T E Ne & $6 / 47 / 53 / 54 / 75 / 83 \mathrm{~A}$ \\
1 & P S T E Ne & $6 / 47 / 75 / 77$ \\
1 & S T E Ne & $6 / 47 / 53 / 54 / 75 / 77 / 42 \mathrm{E} / 81$ \\
1 & P T E & $6 / 47 / 53 / 54 / 75 / 83 \mathrm{~A} / 85$ \\
2 & P T E & $6 / 47 / 53 / 75 / 77$ \\
2 & P & $6 / 47 / 53 / 54 / 75 / 83 \mathrm{~A}$ \\
2 & Sensitive & $6 / 47 / 53 / 54 / 75 / 83 \mathrm{~A}$ \\
2 & Sensitive & $6 / 47 / 53 / 83 \mathrm{~A} / 85$ \\
\hline
\end{tabular}

$\mathbf{P}=$ penicillin $\mathbf{S}=$ streptomycin $\quad \mathbf{T}=$ tetracycline $\mathrm{E}=$ erythromycin $\mathrm{Ne}=$ neomycin

Table III Staph. aureus isolated from noses and skin lesions of patients in a ward for diseases of the skin

\begin{tabular}{|c|c|c|c|c|c|c|}
\hline \multirow[t]{2}{*}{$\begin{array}{l}\text { No. of } \\
\text { Strains Tested }\end{array}$} & \multirow[t]{2}{*}{$\begin{array}{l}\text { Sites of } \\
\text { Origin }\end{array}$} & \multirow{2}{*}{$\begin{array}{l}\text { Antibiotic } \\
\text { Resistance } \\
\text { Pattern }\end{array}$} & \multicolumn{2}{|l|}{ Phage Pattern } & \multicolumn{2}{|c|}{$\begin{array}{l}\text { Percentage of Colonies Sensitive to } \\
\text { Neomycin }\end{array}$} \\
\hline & & & $\begin{array}{l}\text { At Routine } \\
\text { Test Dilution }\end{array}$ & $\begin{array}{l}\text { At } 1,000 \times \\
\text { Routine Test } \\
\text { Dilution }\end{array}$ & $\begin{array}{l}\text { Unstored }(18 \text { hours } \\
\left.\text { in broth at } 37^{\circ} \mathrm{C}\right)\end{array}$ & $\begin{array}{l}\text { After Two Weeks' } \\
\text { Storage in Broth } \\
\text { (room temperature) }\end{array}$ \\
\hline 10 & $\begin{array}{l}\text { Noses and } \\
\text { lesions }\end{array}$ & PSTENe & 85 or $84 / 85$ & - & 0 & 0 \\
\hline 3 & $\begin{array}{l}\text { Noses and } \\
\text { wound }\end{array}$ & PST E M Ne & $29 / 77$ & - & $\mathbf{0}$ & $\mathbf{0}$ \\
\hline $\begin{array}{l}1 \\
1\end{array}$ & $\begin{array}{l}\text { Floor } \\
\text { Burn }\end{array}$ & $\begin{array}{l}\mathrm{Ne} \\
\mathrm{PST} \text { T Ne }\end{array}$ & $53 / 83 \mathrm{~A}$ & $\overline{\mathbf{N}} \mathbf{T}$ & 0 & 0 \\
\hline $\begin{array}{l}1 \\
1\end{array}$ & Nose & $\begin{array}{l}\text { PSTE Ne } \\
\text { T Ne }\end{array}$ & $\begin{array}{l}\text { N.T. } \\
\text { N.T. }\end{array}$ & $\begin{array}{l}\text { N.T. } \\
29\end{array}$ & $\begin{array}{l}\mathbf{0} \\
\mathbf{0}\end{array}$ & $\begin{array}{l}0 \\
3\end{array}$ \\
\hline 1 & Nose & $\mathrm{S} \mathrm{T} \mathrm{Ne}$ & $52 \mathrm{~A} / 79$ & - & $\mathbf{0}$ & 5 \\
\hline 1 & Skin & I No Ne & N.T. & $80 / 81$ & 1 & 88 \\
\hline 1 & Skin & $\mathrm{T} \mathrm{Ne}$ & N.T. & $54 / 75 / 77$ & 4 & 95 \\
\hline 1 & Skin & S T E No Ne & N.T. & $54 / 75 / 77$ & 1 & 60 \\
\hline 1 & Skin & P S T E Ne & N.T. & N.T. & 11 & 86 \\
\hline 1 & Skin & PS T E Ne & $\begin{array}{l}6 / 47 / 53 \\
54 / 75 / 83 A\end{array}$ & - & 15 & 88 \\
\hline
\end{tabular}


14 days. The neomycin-resistant strains were not resistant to bacitracin.

\section{Discussion}

Loss of resistance to an antibiotic at a higher rate than might be expected if the change were due to a chromosomal deletion is one of the characteristics of resistance controlled by extrachromosomal elements or plasmids. Plasmidcontrolled antibiotic resistance in Staph. aureus has been reported for penicillinase production, for resistance to tetracyclines, macrolides, chloramphenicol, and kanamycin or neomycin (eg, Novick, 1963; Harmon and Baldwin, 1964; May, Houghton, and Perret, 1964; Chabbert, Baudens, and Gerbaud, 1964; Hashimoto, Kono, and Mitsuhashi, 1964; Mitsuhashi et al, 1965; Novick and Richmond, 1965; Asheshov, 1966). Evans and Waterworth (1966) reported a loss in resistance to fusidic acid and penicillin in one strain of Staph. aureus and in another strain a simultaneous loss of resistance to fusidic acid, tetracycline, and kanamycin.

In the present study, resistance to neomycin (or kanamycin) and streptomycin was simultaneously lost in some strains on storage for 14 days in broth and a loss of neomycin and tetracycline resistance was found in staphylococci isolated from a patient with eczema after discontinuing neomycin treatment. It seems likely that resistance in these strains was controlled by plasmids, although no increased loss was observed on growing in acriflavine or at $44^{\circ} \mathrm{C}$, and attempts at transduction of neomycin or streptomycin resistance have so far been unsuccessful.

Neomycin-resistant strains of Staph. aureus were isolated in most of the hospitals visited; the overall incidence in noses of patients and staff was $102 / 5,084(2 \%)$ and in lesions $53 / 820$ $(6 \%)$. Phage types $84 / 85$ and $29 / 77$ and related strains were the commonest types of neomycinresistant Staph. aureus isolated in general hospitals and were usually resistant to five or six antibiotics, which often included methicillin. The neomycin-resistant strains originally isolated in the USA, the United Kingdom, and other parts of the world were predominantly phage type $84 / 85$ or related types, but recently phage types $29 / 77$ or 77 have been isolated with increasing frequency in hospitals in the Birmingham region. Neomycin resistance in the strains tested was stable on storage in nutrient broth for 14 days. The neomycin-unstable strains were mainly isolated from patients with skin lesions and were different in phage type from most of the resistant strains isolated in general wards. A high incidence of neomycin-resistant strains in skin lesions $(6 / 17,35 \%)$ was probably related to the widespread use of neomycin in dermatology. Lacey (1968) has shown that neomycin forms insoluble complexes with longchain fatty acids in vivo and suggests that persistence of neomycin in the skin after trea ment might encourage the appearance of iesistant strains.

A wide range of antibiotic sensitivity patteros of Staph. aureus with similar phage type was found in a survey of a ward for patients why skin diseases. A strain resistant to five antibiot and one of a similar phage type, which sensitive to all the antibiotics, were also isolated from different sites on one patient. It seems possible that in some circumstances, a strain $\overrightarrow{\oplus f}$ Staph. aureus growing on a patient may gepn or lose resistance to a number of antibiokscs together, although only neomycin and strepitomycin resistance was shown to be lost in the resistant strains isolated in this ward. Transfer in vivo of antibiotic resistance in Staph. aurefis by transduction has been reported in mouse experiments (Jarolmen, Bondi, and Crowej1, 1965; Novick and Morse, 1967), but no evidegce is available of transfer of resistance in Stą $h$. aureus in man. However, the large populations of Staph. aureus on the skin and in the environment of wards in skin hospitals and in burns units provide an unusual opportunity for transfer of genetic material between stap每lococci.

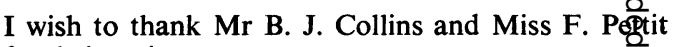
for their assistance.

References

Alder, V. G., and Gillespie, W. A. (1967). Influence of neomixcin sprays on the spread of resistant staphylococci. Lagiet, 2, 1062-1063.

Asheshov, E. H. (1966). Loss of antibiotic resistance in staghylococcus aureus, resulting from growth at high temperatare. J. gen. Microbiol., 42, 403-410.

Ayliffe, G. A. J., and Collins, B. J. (1967). Wound infections acquired from a disperser of an unusual strain of staphylococcus aureus. J. clin. Path., 20, 195-198.

Barber, M., and Kuper, S. W. A. (1951). Identification of staphylococcus pyogenes by the phosphate reaction. J. Path. Blet., $63,65-68$.

Chabbert, Y. A., Baudens, J. G., and Gerbaud, G. R. (1964). Variations sous l'influence de l'acriflavine et transdudujon de la reaction résistance a la kanamycine et au chloramphenicol chez les staphylocoques. Ann. Inst. Paskour, 107, 678-690.

Evans, R. J., and Waterworth, P. M. (1966). Naturally-occufing fusidic acid resistance in staphylococci and its linkage to other resistances. J. clin. Path., 19, 555-560.

Hall, L. B., and Hartnett, M. J. (1964). Measurement o6 the bacterial contamination on surfaces in hospitals. ⿷匚⿳丨コ丨 Hlth Rep. (Wash.), 79, 1021-1024.

Harmon, S. A., and Baldwin, J. N. (1964). Nature of the determinant controlling penicillinase production in staphylocogrus aureus. J. Bact., 87, 593-597.

Hashimoto, H., Kono, K., and Mitsuhashi, S. (1964.) Eling tion of penicillin resistance of Staphylococcus aureus by treatment with acriflavine. J. Bact., 88, 261-262.

Jarolmen, H., Bondi, A., and Crowell, R. L. (1965). TransduQion of staphylococcus aureus to tetracycline resistance in छ্vivo. J. Bact., 89, 1286-1290.

Lacey, R. W. (1968). Binding of neomycin and analogues by gatty acids in vitro. J. clin. Path., 21, 564-566.

Lowbury, E. J. L., Babb, J. R., Brown, V. I., and Collins, (1964). Neomycin-resistant Staphylococcus aureus in a अुrns unit. J. Hyg. (Lond.), 62, 221-228. 
May, J. W., Houghton, R. H., and Perret, C. J. (1964). The effect of growth at elevated temperatures on some heritable properties of Staphylococcus aureus. J. gen. Microbiol., 37, 157-169.

Mitsuhashi, S., Hashimoto, H., Kono, M., and Morimura, M. (1965). Drug resistance of staphylococci. II. Joint elimination and joint transduction of the determinants of penicillinase production and resistance to macrolide antibiotics. J. Bact., 89, 988-992.

Mitsuhashi, S., Morimura, M., Kono, K., and Oshima, H. (1963). Elimination of drug resistance of Staphylococcus aureus by treatment with acriflavine. J. Bact., 86, 162-164.

Novick, R. P. (1963). Analysis by transduction of mutations affecting penicillinase formation in Staphylococcus aureus. J. gen. Microbiol., 33, 121-136.

Novick, R. P., and Morse, S. I. (1967). In vivo transmission of drug resistance factors between strains of Staphylococcus aureus. J. exp. Med., 125, 45-59.

Novick, R. P., and Richmond, M. H. (1965). Nature ano interactions of the genetic elements governing penicillinase synthesis in Staphylococcus aureus. J. Bact., 90, 467-480. 